\title{
Zosteriform Morphea Without History of Herpes Zoster Infection
}

\author{
Hatice ATAŞ, ${ }^{1}$ Müzeyyen GÖNÜL, ${ }^{1}$ Mehmet KOÇAK, ${ }^{1}$ Aysun GÖKÇEE ${ }^{2}$ \\ ${ }^{1}$ Department of Dermatology, Dışkapı Yıldırım Beyazıt Training and Research Hospital, Ankara, Turkey \\ ${ }^{2}$ Department of Pathology, Dışkapı Yıldırım Beyazıt Training and Research Hospital, Ankara, Turkey
}

Morphea is a rare connective tissue disorder. Hardening and thickening of the skin due to an increased density of collagen are its characteristic features. ${ }^{1}$ It has been classified into plaque or circumscribed, linear, generalized, morphea profunda (deep), pansclerotic and combined forms with wide clinical presentation. ${ }^{2}$ Zosteriform morphea (ZM), which is described as a dermatomal distribution of lesions like herpes zoster clinically, is a rare entity. Most of them have been described on the same area of preceding herpes zoster infection as Wolf's isotopic response. ${ }^{3,4}$ In this article, we report a case with usual morphea diagnosed histopathologically at unusual location without history of herpes zoster infection.

An 18-year-old healthy, male patient presented with complaints of hardness and discoloration of the skin at the right posteroinferior side of his trunk with a zosteriform distribution of T10-12 dermatomes, over a period of two years. We detected no characteristic finding in his medical/family history and physical examination except indurated plaque that measured $9 \times 6 \mathrm{~cm}$ in diameter with central hyperpigmentation among the xyphoid and umbilicus that extended to the lateral part of the trunk with atrophic lesions in a zosteriform distribution (Figure 1). We detected no history of herpes zoster or other skin lesions on the site of $\mathrm{ZM}$, abnormal skin moisture, suggestive signs of other extracutaneous, musculoskeletal or systemic sclerosis. Serology for varicella-zoster virus tested negative for immunoglobulin $\mathrm{M}$, but positive for immunoglobulin G. Anti-nuclear antibody, anti-human immunodeficiency virus, first-tier immunoglobulin $\mathrm{M}$ and immunoglobulin $G$ enzyme immunoassays for Borrelia were negative. A skin biopsy revealed an interstitial lymphoplasmacytic infiltrate which surrounded eccrine coils and distributed among separated deep dermal thickened, hypocellular and swollen collagen bundles, and papillary dermal collagen elastic fibers (Figure 2). Laboratory studies including blood cell count, serum chemistry, and autoantibodies (antinuclear antibodies and antiScl-70 also called anti-topoisomerase 1) were all normal or negative. Clinical and pathological features were consistent with the diagnosis of morphea. A written informed consent was obtained from the patient.

Zosteriform term describes the dermatologic morphology attributing to the distribution of herpes zoster. Some diseases such as lichen planus, parakeratosis, common warts, fungal infections, nevus, and skin metastases have been described with this pattern. ${ }^{3}$ Also, several types of cutaneous lesions such as granulomatous dermatitis, vasculitis and folliculitis, granuloma annulare, pseudolymphoma, keloid, sarcoidal granuloma, systemic lymphoma, leukemia cutis, lichenoid dermatitis such as lichen planus and sclerosis, cutaneous Rosai-Dorfman disease have been reported on the site of healed herpes zoster

Received: January 13, 2016 Accepted: May 23, 2016 Published online: August 01, 2016

Correspondence: Hatice Ataş, MD. Dışkapı Yıldırım Beyazıt Eğitim ve Araştırma Hastanesi Dermatoloji Kliniği, 06110 Altındağ, Ankara, Türkiye.

Tel: +90 312 - 5962083 e-mail: drhaticeartik@gmail.com

(2016 Turkish League Against Rheumatism. All rights reserved. 

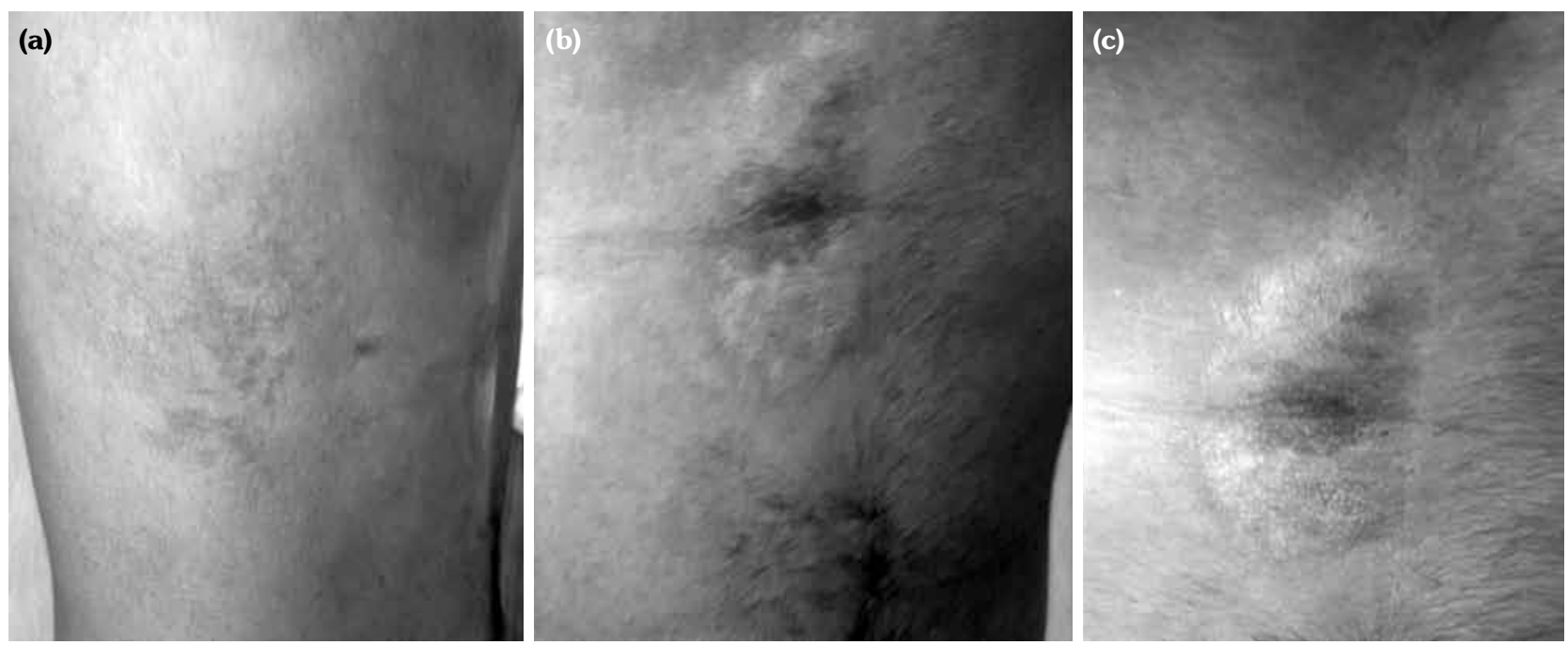

Figure 1. (a-c) Indurated plaque of zosteriform morphea with central hyperpigmentation.

lesions, and this reaction is called as Wolf's isotopic response..$^{5-7}$ Herpes zoster infections may cause atypical delayed-type hypersensitivity reaction to viral antigen or a tissue antigen alteration hypothetically. ${ }^{4}$ A few cases of ZM localized on the site of improved herpes zoster infection have been reported previously. ${ }^{3,4}$ Zoster sine herpete, which has a chronic radicular pain without rash due to varicella zoster virus (VZV) reactivation, should be ruled out from ZM. ${ }^{7}$ Our patient did not have a radicular pain and rash on site of disease. However, VZV deoxyribonucleic acid was not performed. Clinically and pathologically, we evaluated this case as ZM. To our knowledge, only one case was reported as zosteriform pattern without evidence of herpes zoster like our case. ${ }^{8}$

Although trauma ${ }^{9}$ and previous infection (Borrelia burgdorferi) ${ }^{10}$ may incite morphea, the
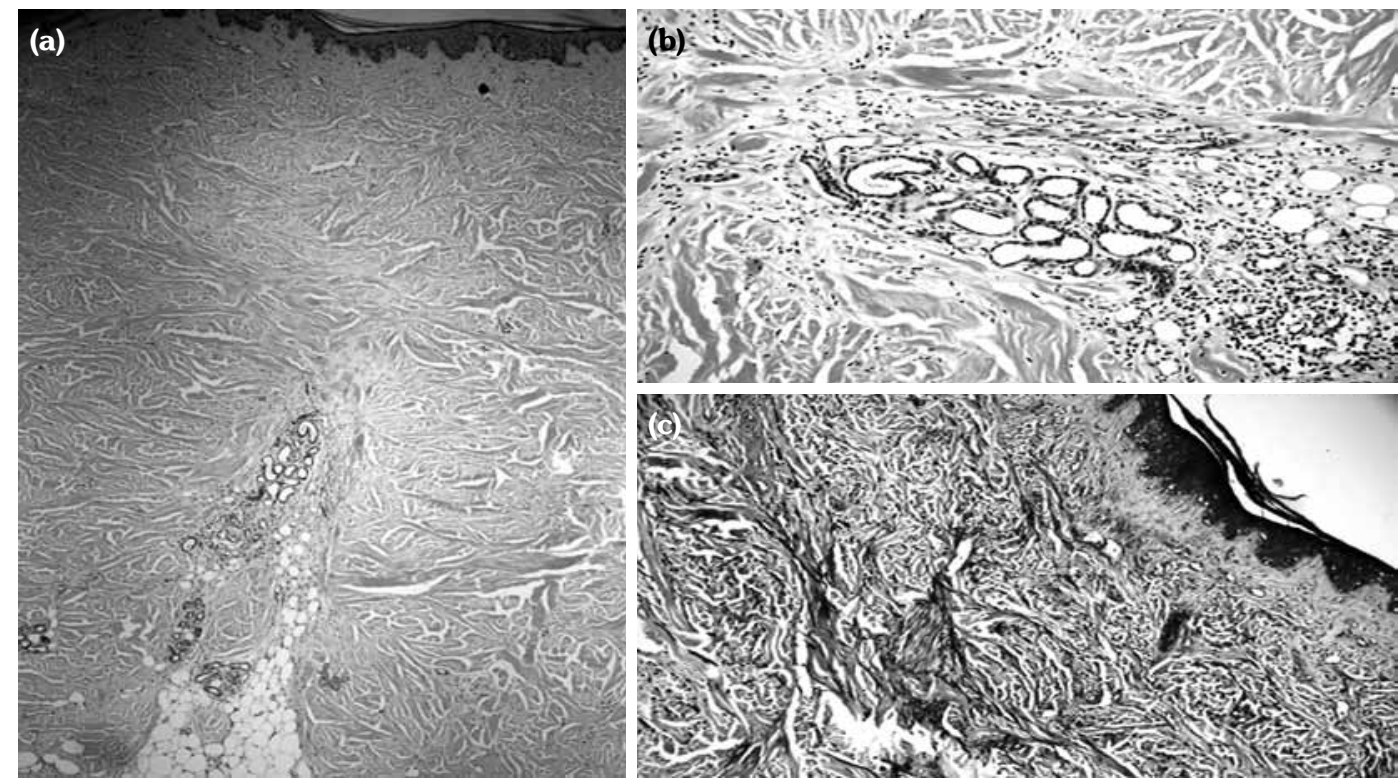

Figure 2. (a) There is an interstitial lymphoplasmacytic infiltrate distributed among deep dermal collagen bundles ( $\mathrm{H}-\mathrm{E} \times 40)$. (b) Collagen bundles thickened, hypocellular and swollen, inflammatory infiltrates separate deep dermal collagen bundles, surround eccrine coils in the dermis (H-E x 200). (c) Papillary dermal collagen elastic fibers with Verhoeff-van Gieson stain (Verhoeff-van Gieson, x 200). 
definitive etiology of morphea is not known. We do not know the reason of zosteriform distribution of morphea, but any neurogenic stimulation may be the cause of dermatomal distribution. Consequently, we presented this case with usual morphea diagnosed with histopathology and of which the location of morphea was unusual and worth to report.

\section{Declaration of conflicting interests}

The authors declared no conflicts of interest with respect to the authorship and/or publication of this article.

\section{Funding}

The authors received no financial support for the research and/or authorship of this article.

\section{REFERENCES}

1. Peterson LS, Nelson AM, Su WP, Mason T, O'Fallon WM, Gabriel SE. The epidemiology of morphea (localized scleroderma) in Olmsted County 19601993. J Rheumatol 1997;24:73-80.

2. Peterson LS, Nelson AM, Su WP. Classification of morphea (localized scleroderma). Mayo Clin Proc 1995;70:1068-76.
3. Ruiz-Villaverde R, Sánchez-Cano D, Galán-Gutiérrez M. Zosteriform morphea: Wolf's isotopic response in an immunocompetent patient. Dermatol Reports 2011;3:e16.

4. López N, Alcaraz I, Cid-Mañas J, Camacho E, Herrera-Acosta E, Matilla A, et al. Wolf's isotopic response: zosteriform morphea appearing at the site of healed herpes zoster in a HIV patient. J Eur Acad Dermatol Venereol 2009;23:90-2.

5. Jaka-Moreno A, López-Pestaña A, López-Núñez M, Ormaechea-Pérez N, Vildosola-Esturo S, Tuneu-Valls A, et al. Wolf's isotopic response: a series of 9 cases. Actas Dermosifiliogr 2012;103:798-805.

6. Requena L, Kutzner H, Escalonilla P, Ortiz S, Schaller $\mathrm{J}$, Rohwedder A. Cutaneous reactions at sites of herpes zoster scars: an expanded spectrum. $\mathrm{Br} \mathrm{J}$ Dermatol 1998;138:161-8.

7. Gilden D, Cohrs RJ, Mahalingam R, Nagel MA. Neurological disease produced by varicella zoster virus reactivation without rash. Curr Top Microbiol Immunol 2010;342:243-53.

8. Joshi A, Al-Mutairi N. Zosteriform morphea: a new pattern. Acta Derm Venereol 2005;85:279-80.

9. Vancheeswaran R, Black CM, David J, Hasson $\mathrm{N}$, Harper J, Atherton D, et al. Childhood-onset scleroderma: is it different from adult-onset disease. Arthritis Rheum 1996;39:1041-9.

10. Aberer E, Neumann R, Stanek G. Is localised scleroderma a Borrelia infection? Lancet 1985;2:278. 